\title{
Participatory Governance - From the Inside Up
}

\author{
Dr. Carol Ann Nelson
}

University of the West Indies, Mona Campus, Jamaica

\begin{abstract}
Macro-economic challenges precipitated the emergence of the Public Sector Memorandum of Understanding (MOU) social partnership agreement between the Government of Jamaica and the Jamaica Confederation of Trade Unions (JCTU). In the context of this governance response to crisis, this paper examines the emergence of Cost Savings Committees (CSCs) as supportive institutional expressions of subsidiarity and innovative governance, to further the MOU strategy of Expenditure Restraint within the public sector. CSCs became a network (node) within the MOU network, pursuing the dismantling and overturning of entrenched, traditional discourses and practices of financial management in the public sector, that had resulted in a culture of abuse and the inefficient management of Government assets and resources. The CSCs' struggles are portrayed in the network connectivity, revealed through the lens of Actor Network Theory and Critical Discourse Analysis (CDA) methodology using text and discourse as units of analysis. Tensions of power and governance are revealed between CSCs and other public sector actor networks in the MOU network of relations, as dimensions of MOU discourse are inculcated concerning financial management, with mixed results. Keywords: actor network; Critical Discourse Analysis; discourse; governance; public sector.
\end{abstract}

\section{Introduction}

In 2004, the Government of Jamaica, issued a circular throughout the public sector, which instituted a cap on public sector employment. The implementation of 'Circular 21', as it was coined, had the objective of stemming the growing costs from public sector salary related expenditures in the budget, with view to help preserve its integrity. This need to curtail increases 


\title{
$9^{\text {th }}$ INTERNATIONAL CONFERENCE ON MANAGEMENT , ECONOMICS AND HUMANITIES
}

\author{
26-28 July, 2019 \\ London, United Kingdom
}

in salary related budgetary expenditure was attributed to the size of the public sector and the related costs and fiscal pressure that it exerted. The union movement, the Jamaica Confederation of Trade Unions (JCTU), took immediate action in response to this unilateral action by Government, given the implications for the JCTU's constituents, which triggered negotiations between themselves and the Government of Jamaica leading to a trade-off and the forging of a consensus. The terms of the arrangement were encapsulated in the text of the social partnership agreement between the Government of Jamaica and the JCTU, called the 'MOU' or the Public Sector Memorandum of Understanding.

The major quid pro quo between the Government and the JCTU was the freezing of wages, concomitant with the maintenance of the current size and cost of wage expenditure for the public sector in exchange for not making 15,000 workers redundant. For the Government, the MOU contributed to fiscal savings by capping the wage bill and by providing a mutual 'breathing space' to address issues surrounding the macro economy. The scope of the MOU was applicable to the entire public sector and it supported the preservation of the existing political and economic governance framework and network of relations. Several principles laid the foundations of the Agreement and three (3) strategies were identified, namely, Employment Constraint, Expenditure Restraint and Wage Restraint. Of the three (3) strategic parameters of the MOU Agreement, the strategy of Expenditure Restraint had the objective to direct a more efficient use of Government resources overall, identify and curtail waste and encourage prioritization in management decision making.

\section{Emergence of Cost Savings Committees (CSCs)}

In support of this strategy, the creation of Cost Savings Committees (CSCs) was advocated with the main objective to monitor the use of assets and expenditure patterns. There was an expectation that CSCS would yield a reduction in Government expenditure by implementing systems to reduce the abuse of Government assets. Created in every Ministry, Department and Agency (MDA) of the public sector, Cost Savings Committees (CSCs) became institutions of governance, (with respect to the remit of financial management and expenditure restraint) and consisted of representatives selected from various sections within MDAs, namely Human Resource Management, Corporate Planning, Civil Service/ Union, etc,. Membership reflected the middle and lower hierarchies of staff of MDAs, thought to be democratically representative of key areas of the respective institutions. 


\title{
$9^{\text {th }}$ INTERNATIONAL CONFERENCE ON MANAGEMENT , ECONOMICS AND HUMANITIES
}

\author{
26-28 July, 2019 \\ London, United Kingdom
}

CSC members attended a programme of orientation and training, as well as receiving guidance on the financial approaches required. Approaches to measures for example, included Absolute Indicators, that measured the total consumption of resources (e.g. the consumption of water in gallons or monetary terms) and Relative Indicators, representing the performance of an organization in relation to its size, production output or number of employees. These facilitated comparisons with previous years and relations to previous production volumes or other significant reference i.e., number of employees, as necessary.

Tables 1 below, indicates that the quantity and cost of water consumed in 2002/03 exceeded the figures for 2001/02. However, the relative indicator (Cost of water consumed per person) shows that in 2002/03 the resource (water) was used more efficiently than in the previous year. Entities were asked to report on cost saving activities such as these as well as qualitative changes in procedures or processes that helped to yield greater efficiency at the end of the year. As part of the cost savings initiative, it was agreed that an allocation of $40 \%$ of the savings garnered from the exercise would be allocated to finance specific benefits for the overall staff, as an incentive for them to continue their efforts.

\section{Table 1: Relative Indicator- Water Consumption}

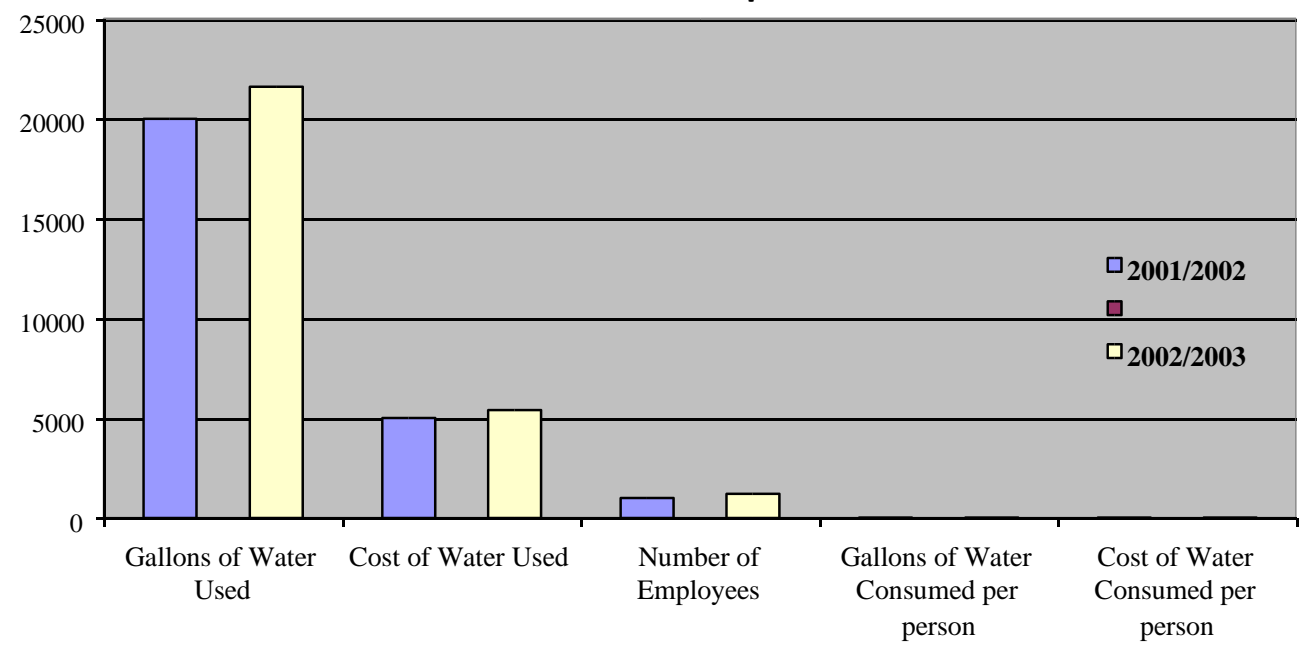

\section{Purpose/Objectives}

Attention to problems, in general, builds on the finding that public sector innovation is often problem-driven (Borins, 2000; Salge, 2011). The strategy of Expenditure Restraint represented the recognition of, as well as a response to, the issue of waste in the public sector. It was an attempt to curtail the entrenched and deemed unacceptable behaviour within the traditional culture and practice of the sector, in terms of how governmental affairs were being managed. This paper explores the formation of the network of relations surrounding the creation and 


\title{
$9^{\text {th }}$ INTERNATIONAL CONFERENCE ON MANAGEMENT , ECONOMICS AND HUMANITIES
}

\author{
26-28 July, 2019 \\ London, United Kingdom
}

implantation of Cost Savings Committees (CSCs), to monitor the use of assets and expenditure patterns. The CSCs' struggles in carrying out their functions from 'inside' institutions are portrayed through network connectivity compared to efforts to engender change from the "bottom up' or 'top down'. These are revealed through the lens of Actor Network Theory and Critical Discourse Analysis (CDA) methodology using text and discourse as units of analysis.

\section{Methodological Approach}

Actor Network Theory (ANT) views the world as consisting of heterogeneous actors in networks of relations, where these actors are interdependent, forming networks by circulating intermediaries amongst themselves - such as a language, a text, a product, or service, for communication. The ontological framework of ANT is unique in recognizing equally both human and non-human actors (Ritzer, 2007) termed 'symmetry,' used to explore the mechanics of actor networks. Being a distinctive approach to social theory and research, (Law, 2007) 'actor networks' is a founding concept of ANT exploring how these are created, held and disintegrated, through social relations involving the alignment and networking of interests in the structuring of power relationships.

The utility of ANT or the sociology of translation as an appropriate theoretical framework resides in the possibilities that it presents to trace the linkages and interactions between actors and to explain how networks and the dynamics of convergence, divergence, stabilization or disintegration. Furthermore, it allows an exploration of the dynamics of network construction, the mechanics of how alliances (Williams-Jones and Graham 2003, 273) are built and to identify the interactions at various levels of the MOU social partnership and institutions as a "lens", to "follow the actors" (Latour 1987, 176).

Translation in ANT consists of four moments, such as problematization, whereby a focal actor identifies an issue around which interests are solicited from various actors, all recognizing mutual benefits to be derived from forming an alliance around it (De Jong, 2007). Interessement which recognizes the defining Obligatory Passage Points or OPPs of the focal actor which becomes indispensable as the other actors have to be convinced to become engaged compulsorily with them in the network to maintain its dynamics given the inequity of access (Callon, 1986).

When negotiations are complete, resulting in the alignment of interests, involving 'trials of strength and tricks Callon (1986, p.10) or 'persuasion, seduction, consent without discussion, 


\title{
$9^{\text {th }}$ INTERNATIONAL CONFERENCE ON MANAGEMENT , ECONOMICS AND HUMANITIES
}

\author{
26-28 July, 2019 \\ London, United Kingdom
}

intrigues, propaganda, violence, transaction, interpretation and even physical violence.' De Jong $(2007$, p. 7$)$ then enrolment is complete, with the network's stability reflecting the effectiveness of the translation process. Mobilization relates to the growth in relations through translation, which enables the actor to grow bigger with more relations to 'black box. The progressive mobilization of actors by the focal actor, causes it to act like a 'single man'. The true macro social form arises when the networks of which the focal actor is constituted disappears into a 'black box' whereby there are no more contests, with the actors, now sealed in fixed stable relationships so a constraining network of relationships exists and equilibrium. Hence a 'macro social' credential is conferred on an actor network, by virtue of other constituents behaving in accordance with its vision of the world conferring the authority to speak on behalf of those translated constituents.

ANT acknowledges the use of text as a means of inscription, as a type of artifact, such as, work routines, legal documents, prevailing norms and habits, written manuals, institutional and organizational arrangements and procedures, within which patterns can be inscribed (Montiero, 2000) and circulated which are vital to secure the interests (Latour, 1992) and maintain connectivity. In the network of relations created, discourse is held to embody these connections which are further explored and deconstructed using Critical Discourse Analysis (CDA) methodology of Norman Fairclough (Fairclough, 1992 ; 2003) which concomitantly provides for a deconstruction of network relations and discourse, to expose hidden power relations as reflected in the relationship between talk and text, discourse practice and their sociological manifestations in context. CDA is 'fluid' enough (Waller, 2009) to be used in conjunction with other types of flexible theories and methodologies such as ANT. Discourse goes beyond text, to include talk and language (Wetherell, et. al., 2001), as well as other elements of social practices, including semiosis, in that CDA views semiosis as an irreducible element of all material social processes (Fairclough, 2000). Hence, social life is seen as an interconnected network of diverse social elements within the network of practices (Fairclough, 2000) that provides data and affords the theorizations of it, to interpret, explain and analyze social behaviour in actor networks in discoursal terms.

Social practices entails discourse, as part of the social activity within the practice which entails using language in a certain way. Discourse is also a part of representation, as social actors produce representations of other practices as well as their own in the course of the activity, within a practice. These in turn, are incorporated into their own practices, as different social actors will again represent them differently, depending on how they are positioned within the practice. Hence representation is the social construction of practices including reflexive selfconstruction, by also entering and being shaped by other social processes and practices. Finally, discourse is 


\title{
$9^{\text {th }}$ INTERNATIONAL CONFERENCE ON MANAGEMENT , ECONOMICS AND HUMANITIES
}

\author{
26-28 July, 2019 \\ London, United Kingdom
}

entailed in 'ways of being' by the constituting of identities which are partly semiotic in construction (Fairclough, 2003).

These moments combine, corresponding to three functions of language and dimensions of meaning which coexist and interact in all discourse, namely the "identity", "relational", and "ideational" functions of language (Fairclough, 1992) reflecting the constructive effects in relation to social identities, subject positions, and relationships between people and systems of knowledge and belief. This multidisciplinary understanding of discourse is merged with a critical dimension, which has its theoretical base within Critical Theory. Broadly speaking, text becomes just one part (Fairclough, 1989) of discourse and social practices that incorporate dialectically, ways of acting and actions, ways of being and representation and ways of identification in terms of the personal and in relation to societal position (Fairclough, 2001).

Participants in the interview process that informed the research were selected from a small knowledge community based on them being 'information rich cases' (Patton, 1987), representing more than $60 \%$ ) of the total population of persons who were directly involved in the creation and development of CSCs. After the first set of interviews and the responses gained, there was an emergence of homogeneity in perspectives in several areas, with a reduction in the diversity, depth and quality of the additional information gleaned, with each successive interview (Guba \& Lincoln, 1985. Explorations were made surrounding other perspectives of the CSCs experience, and interviews were held with 'outliers' (Miles \& Huberman, 1994, p. 28), who related indirectly to the CSCs at various levels regarding financial management and cost efficiency objectives at their level. Focus group type discussions were also held with CSCs as to their challenges of implementation and the responses within their organizations and other internal networked relations in carrying out CSC tasks.

Theme Ordered Matrices were also used to evaluate the dynamics of discursive relations as social practice, to wider socio economic and cultural practices and context, relations of power, genres and orders of discourse and linkages in terms of intertextuality and interdiscursivity. Other techniques such as elements of Constant Comparative Analysis of Grounded Theory (Strauss \& Corbin, 1990) and Case Study Method (Yin, 1994). The use of Case Ordered Effects Matrices (Miles \& Huberman, 1994) assisted to map and derive patterns, constructing meaning across and within groups. 


\title{
$9^{\text {th }}$ INTERNATIONAL CONFERENCE ON MANAGEMENT , ECONOMICS AND HUMANITIES
}

\author{
26-28 July, 2019 \\ London, United Kingdom
}

\section{Outcomes}

The cost savings principles of the MOU had intertextual origins in the "Orane Report" which contained the findings of a review conducted on the operations of Government including recommendations to curtail waste and excesses as a 'manifestation of a crisis in Government (Orane Report, 2002). Intertextuality involves, referencing and incorporating, re-contextualizing, transforming and dialoguing with other texts, which is inextricably linked to what is made "explicit," signalling what is left "implicit" (Fairclough, 2003). With respect to discursive practices and the factors influencing the interpretation of the strategy of Expenditure Restraint, there are previous discourses concerned with reducing public expenditure, which have influenced text production. The Report indicated that although regulations existed, the level of compliance was weak due to improper management practices and senior public officials acting unilaterally.

The Report makes mention of other studies, (Nettleford,1992; Jenkins,1994) that have made recommendations on the matter of waste in public expenditure (to which its own text pays recognition and to which the strategy of Expenditure Restraint in the MOU, also links intertextually and interdiscursively. The Orane Report made recommendations to reduce waste in several areas, very similar to those warranting attention within the text of the MOU Agreement, such as, rental and space utilization, utility costs, use of consultants, domestic and overseas travel, Government Overseas Missions \& Agencies, abuse of Government vehicles and waste, by unnecessary expenditures for stationery, furniture and newspapers.

From the recommendations of the Orane Report one initiative emerged that resulted in MDAs adopting cost saving measures but specific to energy related consumption through the creation of 'Energy/Efficiency Committees' (EECs). Whether by error or design, it was apparent that these EECs resonated in several aspects with the remit of the CSCs and it was noted from the outset that certain synergies could be built between them under the MOU. It was noted that the outputs and information generated from the EECs could inform the assessments of cost savings within the context of the CSCs, whereby Chairpersons of the EECs were automatically incorporated into CSCs. The strategy of Expenditure Restraint sought to undermine the genre of waste in the public sector and the activities of government through the CSCs, undergirded by a cultural/ social a social axiom that government resources and taxpayers' dollars were of an endless supply and secondly, to address concerns of the culture and practices within the management of the public sector that demonstrated a lack of accountability in the use of Government resources.

As an innovative approach to improve the governance of financial management activities, the CSCs were to address the weaknesses of financial management from the 'inside up,' and from "within', being expected to take an alternative approach, different perspective and to probe 


\title{
$9^{\text {th }}$ INTERNATIONAL CONFERENCE ON MANAGEMENT , ECONOMICS AND HUMANITIES
}

\author{
26-28 July, 2019 \\ London, United Kingdom
}

further than was customary. The role of the CSCs included looking at processes and the operations of entities to yield efficiencies through changes in management, inclusive of broader financial management and policy related concerns. The need for the implementation of systems to monitor expenditure patterns and the use of assets, with a view to reducing abuse and expenditure, fell within the same frame of reference.

From the perspective of ANT, executing the tasks of the CSCs impinged upon issues of genre and cultural attitudes by encouraging interessement through an acknowledgement of the problem of waste and then enrollment firstly, by the Committee members themselves and thereafter through their activities, to enlist staff at various levels to exhibit their "buy-in' to a cost savings discourse and practice accordingly, as a sub set of the overall MOU social partnership discourse and practice. As a dimension of MOU discourse and practice, cost savings in the public sector, the strategy of cost containment, cost efficiency in use of human and public sector resources would require the inculcation of a 'new' discourse practices with implications for overturning the traditional discourse and accepted practices operational within the public sector. Certain adjustments to power relations are also implied relating to the inclusion of the Strategy of Expenditure restraint in the first instance and reinforced by the formation of institutions such as CSCs within the broader social partnership.

This initiative led by the CSCs, was met with resistance within some entities, being faced with issues of power and contention also compounded by the lack of definition of the scope and authority of these institutions arising from within a variety of established institutional contexts and culture. Moreover, that the furtherance of objectives of the CSC would contend with the established culture and practice of "how business is done'. Several CSCs referenced the excesses of higher management and the example that needed to be set from senior directorate levels. In addition, there were issues in the way the efforts of the Committees were interpreted and operationalized within each entity in the realm of the social/ public sector networks that they were a part of as well as the scope of the expectations, authority and change engendered.

Challenges would arise where the recommendations and decisions of the CSCs were ignored especially if they were in contradiction to the wishes or years of accepted practice within bureaucratic regimes and governance hierarchies. Given the political nature of the issues, whether partisan or not, it surfaced that certain persons acted and pursued practices in their own interest especially where they were buttressed empowered or supported by organizational and party related political power forces and deemed untouchable. 


\title{
$9^{\text {th }}$ INTERNATIONAL CONFERENCE ON MANAGEMENT , ECONOMICS AND HUMANITIES
}

\author{
26-28 July, 2019 \\ London, United Kingdom
}

There was a recognition that the efforts of cost savings sought to address the heart of the public sector's culture and attitude, which was entrenched in a broader societal culture, that overflowed into public sector discourse, specific to the treatment of "government' property or resources, exemplified in the following statement, by a participant.

we have this tendency where government properties are concerned and things pertaining to government expenditure, that people on the whole just say its government something' and 'government paying for it' you know, so they go ahead and spend'

Fairclough $(2001 ; 2003)$ explains that socio-cultural and historical dynamics, are important to further the understanding of discourse and its implications. There was also the inference by the attitude displayed, by public sector employees, that they were unable to perceive the levels of connectivity between themselves and Government property. There is a lack of consciousness or awareness that the income Government receives from taxation and services etc., comes from individuals, consumers, activities in the economy and the public sector employees themselves, which would be directly or indirectly spent or wasted.

Additionally, there was the view that the budgetary process mitigated against encouraging and motivating staff towards cost savings, as the savings made in a specific area resulted in a reduction in the budgetary allocation given in that area due to the demonstration of a more efficient usage. Furthermore, specific savings realized were absorbed into the general pool or Consolidated Fund and became 'invisible', leading to the perspective that there was no real gain or improvement and hence no incentive to pursue the initiative. The suggestion was that the 'saved' resources should have been "creamed off", separated or pooled collectively, being placed into an account so it could remain distinctive recognizing the source of each contribution. In this way the saved resources would have remained visible to those making cost savings efforts, contributing inputs and for tracking improvements or changes over time, rather than being absorbed within the overarching Consolidated Fund.

Perspectives were raised that the Cost Savings thrust was innovative and had transformative capacity (Bland, et.al., 2010) but it should have been systematized and structured with specific parameters of accountability on the part of senior management, incorporated as part of their mandate.

This would have the intention of stimulating management to respond to specific requirements and to factor these in various programmes and planning. Conversely, there was the perspective that the genesis of the alternative "inside up" approach being pursued through the institution of the CSCs in the first instance was due to the failure of the same "top down' approach to begin with, as according to Boin \& Goodin, (2007) it is possible for over-institutionalized 


\title{
$9^{\text {th }}$ INTERNATIONAL CONFERENCE ON MANAGEMENT , ECONOMICS AND HUMANITIES
}

\author{
26-28 July, 2019 \\ London, United Kingdom
}

structures to lose some of their utility for governance. The reporting relationship and the weight accorded to recommendations and decisions of the Committee as against the existing bureaucratic regimes and governance hierarchies and structures were a contested one, sometimes resulting in no action on the matters raised. This signalled the lack of recognition and diminished authority ascribed to CSCs within their organizations, by staff, reflected also in parameters of their power relations within the organization as their activities were interpreted as contesting prevailing power regimes of decision makers and the status quo.

The perceived contests and lack of action taken on matters raised by the Committee also has the converse effect of demotivating Committees and fostering fractured relationships deconstructing elements of collaborative governance (Bommert, 2010). These perceptions accentuated the framing of the Committee, on the part of the organization in which it was embedded, as being a situation of the organization or 'us' against 'them', meaning the Committee. Further, other concerns emerged accordingly as newly formed and poorly institutionalized networks found it difficult to work effectively with other actors, perhaps fearing that the interface could stymie or undermine their own developmental processes (Boin \& Goodin, 2007). Another consideration was the absorptive capacity of the public sector system to accommodate additional functions and responsibilities within a context of limited resources and the possibility of the duplication of efforts in order to etch out higher degrees of compliance as well as obtain cost savings targets. Other issues emerging from the discourse were the lack of available manpower to devote to the cost savings efforts given the staff shortages that existed within public sector entities.

One could question whether the creation of the CSCs implied the inability of the existing financial management regime to adequately police operations especially with respect to financial management concerns, hence warranting an additional supporting initiative even to the point of being superimposed. The MOU having conferred authority and legitimacy to CSCs initiatives raised critiques whether more measures could have been taken to strengthen or still is required to address gaps or to support existing institutions of financial management regardless of the input of CSCs. Further, that deploying limited resources and personnel towards initiating the new CSCs, although innovative, could lead to undermining pre-existing structures as well as stymie the effectiveness of the CSCs initiative. 


\title{
$9^{\text {th }}$ INTERNATIONAL CONFERENCE ON MANAGEMENT , ECONOMICS AND HUMANITIES
}

\author{
26-28 July, 2019 \\ London, United Kingdom
}

\section{Implications}

As an intermediary, the text of the MOU Agreement and its discourse has influenced the development of institutions, initiated cultural change, configured human relationships, interactions and associations amongst and between the key partners or actors of the social partnership, namely the public sector and trade union movement. CSCs created in the context of the MOU were indicative of a shift in the mode of governance of the public sector toward engendering change from the "inside up's as against top down approaches. The discourse of the MOU social partnership through the strategy of Expenditure Restraint, initiated a "new governance' modality or thrust, in seeking to inculcate cost savings, more stringent monitoring and addressing issues of financial management. The challenges of transforming the discourse of the civil service within the traditional public sector culture of their institutions and their practices were foregrounded and the innovative CSCs created served as a "inside up' conduit to engender transformation from within. According to Fairclough $(2004$, p.113) for

'creative partnerships to go beyond the realm of imaginary construal into the realm of actual existence, people would need to start acting and interacting differently, and being different. Partly these enactments and inculcations are themselves semiotic, entailing new genres, and new styles. But partly they are non-semiotic....'

The implications for multilevel empowerment and relations of power within the public sector, captures the idea of multiple interacting authority centres and the decentralizing of power inwards. The network relations created in the context of the empowerment of the CSCs was a contested one, especially transparent when they embarked on taking measures contravening pre-existing management stances, for example, on procurement matters, which results in the 'contest of wills' (Callon \& Latour, 1981). The delegation of cost savings authority and policy initiatives that empowered the 'middle' within the respective institutions, exercised a form of internal governance from the "inside up', which in turn, had implications for the financial management practices of the senior, upper hierarchies of institutions. The Cost Savings Committee's role was distinct from its forerunner of the Energy/Efficiency Committees, going further than these, to include remedies to embrace and act on initiating the change required in the processes and operations of entities to yield efficiencies through change management. The initiation of CSCs as an additional tool of governance or mechanism of financial management from 'within,' internal to the respective organizations, can imply that traditional structures and approaches, usually born of 'top down' initiatives and institutional frameworks have not been as effective. 


\section{$9^{\text {th }}$ INTERNATIONAL CONFERENCE ON MANAGEMENT , ECONOMICS AND HUMANITIES}

\section{Conclusion}

The discourse of the MOU social partnership agreement and practice of new governance, as prescribed in text, initiated the development of CSCs to be used as a subsidiary tool of governance with implications for engendering a culture of cost savings, enhanced accountability and monitoring efficiency with respect to the financial management practices of the public sector. The MOU Agreement and discourse catalysed several processes in its network of relations which simultaneously, had implications for governance, the autonomy of the state in decision making, the nature of the reforms for the public sector, human resources management and capacity building within the sector.

The CSCs created actor network relationships with the institutional network within which they were embedded, representing MOU discourse and practice accordingly, while concurrently being positioned as an actor within the MOU actor network, with the role of furthering a cost savings discourse of 'revitalized' financial management governance re the social partnership agreement. The CSCs represented an innovative mechanism, providing an opportunity to foster change, away from the entrenched culture of inefficient financial management practices engendering waste as part of the traditional discourse. The 'status quo' cultural practices within public sector management were challenged with the emergence of CSCs as representative institutions and instruments of 'new' MOU governance within the public sector. The purposes of the CSCs were emancipatory, to locate cost savings and negative financial management practices and to overturn and realign them, within the context of operationalizing the MOU discourse and practice of cost savings efficiency and 'new governance', whilst engendering broad based, democratic participation.

CSCs had to 'buy into', cost saving imaginaries, inculcated as new ways of being for themselves with a view to network with public sector staff to also 'come into their own/ interessement' through participation (enrollment) and developing measures jointly with management. Mixed benefits emerged from CSCs being empowerment within the organization, where the positioned themselves, to act, think and talk and see themselves ideationally, in terms of the new 'MOU discourse' of 'cost savings'. 


\section{$9^{\text {th }}$ INTERNATIONAL CONFERENCE ON MANAGEMENT , ECONOMICS AND HUMANITIES}

\section{References}

Bland, T., Bruk, B., Kim, D., and Lee, K. T. (2010). Enhancing public sector innovation: Examining the network-innovation relationship. The innovation journal: The public sector innovation journal, 15(3), 1-17.

Boin, A., \& Goodin, R. E. (2007). Institutionalizing upstarts: The demons of domestication and the benefits of recalcitrance. Acta Politica, 42(1), 40-57.

Bommert, B. (2010). Collaborative innovation in the public sector. International public management review, 11(1), 15-33.

Borins, S. (2000). Loose cannons and rule breakers, or enterprising leaders? Some evidence about innovative public managers. Public Administration Review, 60(6), 498-507.

Callon, M. (1986). The sociology of an actor-network: The case of the electric vehicle. In Mapping the dynamics of science and technology (pp. 19-34). Palgrave Macmillan, London.

de Jong, B. (2007). Shedding Light on the darkness: Using the Actor-Network theory to analyse the distribution of power. Paper for the 47th Europe Regional Science Association.

Fairclough, N. (1989). Discourse and power. Language and power. London: Longman.

Fairclough, N. (1992). Discourse and text: Linguistic and intertextual analysis within discourse analysis. Discourse \& Society, 3(2), 193-217.

Fairclough, N. (2000). Discourse, social theory, and social research: The discourse of welfare reform. Journal of sociolinguistics, 4(2), 163-195.

Fairclough, N. (2001). Language and power. Pearson Education.

Fairclough, N. (2003). Analysing discourse: Textual analysis for social research. Psychology Press. Fairclough, N. (2004). Critical discourse analysis in researching language in the new capitalism: Overdetermination, transdisciplinarity and textual analysis. Systemic functional linguistics and critical discourse analysis, pp.103-122.

Guba, E. G., \& Lincoln, Y. S. (1985). Naturalistic inquiry.

Jenkins, K. (1994). Jamaica: Public Service Reform. unpublished report to the government of Jamaica, January 1, 1994.

Latour, B. (1987). Science in action: How to follow engineers and scientists through society.

Cambridge: Harvard UP. 


\section{$9^{\text {th }}$ INTERNATIONAL CONFERENCE ON MANAGEMENT , ECONOMICS AND HUMANITIES}

\section{6-28 July, 2019 \\ London, United Kingdom}

Latour, B. (1996). Aramis, or, the love of technology (Vol. 1996). Cambridge, MA: Harvard University Press.

Law, J. (1991). A sociology of monsters: Essays on power, technology and domination. London: Routledge.

Law, J. (1992). Notes on the theory of the actor-network: Ordering, strategy, and heterogeneity. Systems Practice, 5(4), 379-393. doi:10.1007/BF01059830

Law, J. (2007) Actor Network Theory and Material Semiotics. Centre for Science Studies and

Department of Sociology, Lancaster University. Retrieved from www.heterogeneities.net/publications/Law-ANTandMaterialSemiotics.pdf

Miles, M. B., Huberman, A. M., Huberman, M. A., \& Huberman, M. (1994). Qualitative data analysis: An expanded sourcebook. Sage.

Monteiro, E. (2000). Actor-network theory and information infrastructure. From control to drift: The dynamics of corporate information infrastructures. pp.71- 83.

Nettleford R (1992) 'Report of Committee of Advisors on Government Structure, Ministry of Finance \& Planning, Government of Jamaica.

Orane, D. (1999). Orane Report (Task Force to Reduce Waste in the Public Sector). Kingston, JM. Patton, M. Q. (1987). How to use qualitative methods in evaluation (No. 4). Sage.

Ritzer, G. (Ed.), (2007). The Blackwell encyclopaedia of sociology (Vol. 1479). Malden, MA: Blackwell Publishing. doi:10.1111/b.9781405124331. 2007.x

Salge, T. O. (2011). A behavioural model of innovative search: Evidence from public hospital services. Journal of Public Administration Research and Theory, 21(1), 181-210.

Strauss, A., Corbin, L., \& Juliet, M. (1998). Basics of qualitative research: techniques and procedures developing grounded theory. Thousand Oaks: Sage.

Waller, L. G. (2009). The role of discourse in ICT for development: Lessons from Jamaica. VDM Publishing.

Wetherell, M., Taylor, S., \& Yates, S. J. (2001). Discourse theory and practice: A reader. Sage. Widdowson, H. G. (1998). Context, community, and authentic language. TESOL quarterly, 32(4), 705-716.

Williams-Jones, B., \& Graham, J. E. (2003). Actor-network theory: a tool to support ethical analysis of commercial genetic testing. New genetics and society, 22(3), 271-296.

Yin, R. (1994). Discovering the future of the case study. Method in evaluation research. Evaluation practice, 15(3), 283-290. 